\title{
The Surplus of Signification
}

Merleau-Ponty and Enactivism on the Continuity of Life, Mind, and Culture

\section{Hayden Kee}

Journal of French and Francophone Philosophy - Revue de la philosophie française et de langue française, Vol XXVIII, No 1 (2020) pp 27-52

\author{
Vol XXVIII, No 1 (2020) \\ ISSN 1936-6280 (print) \\ ISSN 2155-1162 (online) \\ DOI 10.5195/jffp.2020.919 \\ www.jffp.org
}

\section{(oc) EY-NG-NO}

This work is licensed under a Creative Commons Attribution-Noncommercial-No Derivative Works 3.0 United States License.

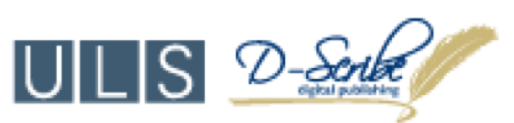

This journal is operated by the University Library System of the University of Pittsburgh as part of its D-Scribe Digital Publishing Program, and is co-sponsored by the University of Pittsburgh Press 


\title{
The Surplus of Signification
}

\author{
Merleau-Ponty and Enactivism on the Continuity of Life, \\ Mind, and Culture
}

\author{
Hayden Kee \\ Fordham University
}

One of the most innovative aspects of enactivism, beginning with 1991's The Embodied Mind ${ }^{1}$, was its insistence on placing lived experience at the center of cognitive science research. To that end, early enactivists drew inspiration from phenomenology and non-Western traditions (especially Buddhist and Yogic) of reflection upon experience. Among the phenomenologists, enactivism found a natural ally in Merleau-Ponty. Much more so than his German predecessors, Merleau-Ponty moved freely between empirical and phenomenological research, allowing the findings of each to be revised and refined in light of the other. Hence, the authors of The Embodied Mind credit Merleau-Ponty with being one of the few in the Western tradition "whose work was committed to an exploration of the fundamental entre-deux between science and experience, experience and world."2

Beyond this methodological convergence, Merleau-Ponty also exhibited an interest throughout his writings in numerous central themes of enactivist thought. One of these is what has come to be known in contemporary cognitive science as the life-mind continuity thesis: the idea that there are basic organizational properties common to the organic domain and the mind, with the latter being an enrichment of the former. ${ }^{3}$ In his investigations into animal psychology and the philosophy of biology, Merleau-Ponty presented rich resources for enactivists to mine in their formulation of the life-mind continuity thesis. However, in the same writings we also find stark assertions of the differences between various types of organic, sensorimotor, and intelligent creatures. This is especially true where the phenomenological dimension of life-mind continuity is concerned. This is the idea, inspired by the phenomenologist Hans Jonas, that certain features of (paradigmatically) human experience described by existential phenomenologists apply throughout the organic domain to the experience of all living beings. 
I will argue that in their adoption of Merleau-Ponty, enactivists ought to pay greater attention to the differences he stressed within continuity. Moreover, returning to a Merleau-Pontian version of the life-mind continuity thesis can provide enactivists with a more defensible version of phenomenological continuity. Returning to Merleau-Ponty clarifies the role of phenomenology within enactivism. And it responds to confusion generated by the application of phenomenological concepts to describe the "experience" of creatures that have no phenomenal consciousness, thus undermining allegations of anthropomorphism. ${ }^{4}$ It also suggests an account of the continuity-amid-discontinuity between humans and other higher animals that fills in this chapter of the enactivist story while avoiding the uncomfortably stark dualism of content-involving and non-content-involving minds with which some radical accounts are saddled. ${ }^{5}$ However, as we will see, a few slight modifications to Merleau-Ponty's view are required in light of new findings in comparative and developmental psychology from recent decades.

In the first part of this paper, I discuss enactivism's life-mind continuity thesis, its phenomenological dimension in particular. I criticize on textual grounds the appeal to Merleau-Ponty, arguing that he held a view of continuity that is importantly at odds with the enactivist view, especially where organisms with no sensorimotor system are concerned. On phenomenological and philosophical grounds, we should side with MerleauPonty. In the second part, I explore the prospects for a revised MerleauPontian continuity thesis within contemporary enactivism. I discuss MerleauPonty's views on the continuity and discontinuity between the cognition and experience of humans and that of nonhuman higher animals. Though there is an astonishing convergence between Merleau-Ponty's views and views that can be found in the most recent developmental and comparative psychology, I claim that Merleau-Ponty slightly overestimates the differences between human cognition and that of our closest primate kin. Viewing uniquely human modes of cognition in a developmental light allows us to reassert a stronger continuity (amid discontinuity) between human cognition and experience and that of higher animals.

\section{Merleau-Ponty and Enactivism on Life-mind Continuity}

\section{Enactivism's life-mind continuity thesis}

The life-mind continuity thesis is a central component of the enactivist account of life and mind. ${ }^{6}$ Stated succinctly, it maintains that "life and mind share a set of basic organizational properties, and the organizational properties distinctive of mind are an enriched version of those fundamental to life." ${ }^{7}$ Different authors defend different versions of the thesis, and sometimes different aspects within one version. I will focus on Evan 
Thompson's version, as he has presented it in Mind in Life and other works, drawing on the autopoietic theory of life developed by Maturana and Varela and phenomenological approaches to life and behavior developed by Hans Jonas and Merleau-Ponty (though, as I shall suggest presently, this "Jonasand-Merleau-Ponty" coupling may not be as felicitous as is sometimes assumed). ${ }^{8}$

There are two aspects to Thompson's life-mind continuity thesis, which we might call the empirical and phenomenological dimensions of life-mind continuity. The empirical dimension is determined by the autopoietic conception of life drawn from Varela's and Maturana's work in theoretical biology. Varela provides a simplified definition of an autopoietic system. ${ }^{9}$ For a system to be autopoietic,

(i) the system must have a semipermeable boundary; (ii) the boundary must be produced by a network of reactions that takes place within the boundary; and (iii) the network of reactions must include reactions that regenerate the components of the system. ${ }^{10}$

An autopoietic system is a self-producing, self-sustaining entity individuated from its surroundings by its boundary. At the same time, enactivism extends the concept of cognition to apply to all living systems defined as autopoietic systems. On the enactivist account, "cognition" simply involves acting or behaving towards the organism's environment in ways that are relevant for the production and sustenance of the organism. In this respect, all organisms, not only those with nervous systems, are autopoieticcognitive systems. ${ }^{11}$ The most basic case, one often used as an illustration in enactivist writings, is the unicellular organism. ${ }^{12}$

What, then, of the phenomenological dimension of life-mind continuity? This is where Jonas enters the picture. Jonas provides a phenomenological interpretation of basic biological phenomena. The key notion for him is metabolism. Jonas' claim is that wherever we find the chemico-biological processes of metabolism, the energetic processes through which an organism produces and sustains itself, we find also in nuce the same existential conditions that shape human existence. As such, the same categories used by phenomenologists and existentialists to describe human existence can also be predicated non-equivocally of a unicellular organism. As Jonas puts it, "the great contradictions which man discovers in himself [...] have their rudimentary traces in even the most primitive forms of life." ${ }^{13}$ Just as the autopoietic notion of cognition applies to all living things from the simplest autopoietic entities up to complex animals, so, too, for Jonas and those enactivists who follow him, phenomenological-existential categories apply from humans all the way down to the simplest metabolic creatures. The domain of creatures covered by the autopoietic dimension of the life-mind continuity thesis is thus coextensive with that covered by the Jonasian 
existential-phenomenological one. They are complementary theses, describing the same phenomena from the objective and subjective perspectives respectively.

My main purpose is not to assess the autopoietic-empirical and Jonasianphenomenological versions of the life-mind continuity thesis on their own merits. Hence, these brief sketches will suffice for present purposes. I am more concerned to ask whether Merleau-Ponty's own view on life-mind continuity (a term, to my knowledge, that he never employs ${ }^{14}$ ) complements the Jonasian-autopoietic synthesis just as comfortably as those Jonasian and autopoietic aspects fit together. Prior to the chapters discussing autopoiesis and the Jonasian philosophy of the organism in Thompson's Mind in Life, we find a chapter on Merleau-Ponty's first book, The Structure of Behavior. Merleau-Ponty's objective in Structure is to "understand the relationships of consciousness and nature"15 - and, indeed, this remains one of the guiding objectives of his entire oeuvre. To that end, in Structure, Merleau-Ponty surveys a broad array of studies on animal behavior to conduct an immanent critique of the notion of behavior as employed in the psychology of his time. He attempts gradually to show the cracks in the objectivist conception of behavior (e.g., that of behaviorism), demonstrating the need for a phenomenologically informed approach. Merleau-Ponty understands behavior as a structure, or form: a whole in which the parts can only be understood with reference to the whole.

This cashes out in various ways for the understanding of behavior. For one, against approaches that attempt to understand behavior as a sort of elaborate conditioned reflex, Merleau-Ponty finds that behavior is always an achievement of the whole organism, comprising the nervous system and the rest of the body. It is not the independent function of this or that isolated neural mechanism or body part. Further, such behavior can only be understood as the coupling of the organism with its environment. The latter cannot be understood as objectivistically described array of pure stimuli, but must be understood in the sense it has as construed by the conscious organism. And individual acts of perception and behavior must be understood in the broader significance that they have in the life of the organism. In all of these respects, behavior is a whole, structurally and internally determined by the interrelation of its moments. Ultimately, consciousness and nature themselves cannot be understood as opposed and isolated domains. At least where the robust notion of behavior is concerned, they must be seen as internally and structurally interrelated. ${ }^{16}$

Let us return now to Thompson's view of life-mind continuity in Mind in Life. In elaborating the phenomena of mind, life, and experience from different dimensions, Thompson has now introduced three distinct perspectives (autopoietic, Jonasian, and Merleau-Pontian), each of which can be seen as contributing something to the life-mind continuity discussion. But is the Merleau-Pontian notion of behavior-as-structure coincident with the Jonasian 
phenomenological interpretation of metabolism and the autopoietic account of cognition? ${ }^{17}$ Does it, too, admit a foundational continuity running from the simplest cases of unicellular life right up to the higher instantiations of animal mind and life?

\section{Merleau-Ponty on life-mind continuity}

In this section, I will argue that, contra Jonas, Merleau-Ponty does not admit a phenomenological dimension to life-mind continuity that runs all the way down from human experience to the "experience" of unicellular organisms. Disentangling Merleau-Ponty's view from those of Jonas and enactivism will not only help us establish historically and exegetically what the various authors thought on these topics. I will also suggest that recovering a uniquely Merleau-Pontian view points the way towards a qualified version of the life-mind continuity thesis that is more defensible than the one presented by Jonas and Thompson. It is a view of continuity, however, that admits greater discontinuity amid continuity than the Jonasian and autopoietic versions of continuity often tend to acknowledge.

Let us first consider the purely textual basis for adjudicating this issue. We begin with The Structure of Behavior, as it is the work most often cited in enactivist discussions of life-mind continuity, and the published work in which Merleau-Ponty discusses the greatest number and variety of examples of animal behavior. The first thing to recall here is that Structure is a book about animal behavior. Amid the myriad examples of behavior discussed, Merleau-Ponty at no points ascribes "behavior" to any creature outside the animal kingdom. Indeed, among the animal's whose behavior Merleau-Ponty discusses, almost all have central nervous systems. ${ }^{18}$ Further, as already mentioned, the objective of Structure is to understand behavior as the structural relationship between consciousness - sentience, phenomenal consciousness - and nature. As there is little reason to believe that MerleauPonty ascribes consciousness to any living being outside the animal kingdom (and Thompson explicitly maintains that, as best we can tell, a nervous system is required for consciousness - see below), we should also refrain from attributing behavior to non-sentient creatures. Finally, in his characterization of the simplest forms of behavior, Merleau-Ponty states that even these are "never addressed to isolated objects and always depend upon a large number of external conditions." 19 Whether this is true of the putative "behavior" of unicellular organisms would require a lengthier discussion than can be pursued here, but one can certainly doubt that it is. Moreover, in this context, Merleau-Ponty also states that the simplest forms of behavior are "those for example that are found in invertebrates." 20 This does not quite amount to stating explicitly that the simplest forms of behavior are not also found in creatures of lesser complexity than invertebrates or in creatures outside of the animal kingdom. Nonetheless, given the focus of the work on the sensorimotor action of animals with nervous systems, it seems on the balance 
of evidence sufficiently clear that Merleau-Ponty's concept of behavior applies only to animals with nervous systems that are at least minimally sentient.

Structure was Merleau-Ponty's first published monograph. He would continue to reflect and write about animals throughout his later work. Still, with very few exceptions, his focus is on the sensorimotor behavior and experience of animals with nervous systems. One exception of particular interest for present purposes occurs in Merleau-Ponty's Sorbonne lectures on Human Sciences and Phenomenology from the early $1950 \mathrm{~s}^{21}$, where there is a brief discussion of how to interpret the activity of an amoeba, a unicellular organism. ${ }^{22}$ Here, Merleau-Ponty explicitly denies that the activity of the amoeba can be understood as "behavior" and in any way compared to human or other animal behavior. He refers to the attempt to do so as an "error of biologists who attempt to account for the behavior of unicellular beings with the aid of categories from human behavior." 23 This error results from "an anthropomorphic conception of these tropisms which projects the contents of human activity into them." But, Merleau-Ponty insists, "There is no common standard between tropisms and human actions: tropisms are a manner of elementary reaction, while human actions almost never offer a constancy of this sort." 24

It is worth mentioning here that one of the main objections that has been raised against the phenomenological dimension of the enactivist life-mind continuity thesis is precisely that it is anthropomorphic and risks grossly misinterpreting the nature of nonhuman life and consciousness by projecting structures and categories of our own experience onto nonhuman creatures. ${ }^{25}$ In light of this perceived danger, De Jesus has urged enactivists to turn away from phenomenology. But as we have just seen, at least where the amoeba is concerned, Merleau-Ponty entirely agrees with the allegations of anthropomorphism that are cast against a (Jonasian) "phenomenological" interpretation of unicellular life. This does not, however, entail that MerleauPonty is opposed to any and all anthropomorphism in the interpretation of animal life. Where there really is continuity between human behavior and the behavior of nonhuman animals, Merleau-Ponty urges that the latter must be interpreted with the aid of an "indispensable anthropomorphism." ${ }^{26}$ Unlike Jonas and Thompson, however, Merleau-Ponty (at least in Structure and the early 1950s lectures) thinks that applying categories from human existence to unicellular life is not a case of necessary and beneficial anthropomorphism, but of a pernicious anthropomorphism.

A final group of texts to consider in this discussion are the notes from Merleau-Ponty's courses on nature, delivered at the Collège de France from 1956-1960. These are of interest both for their detailed discussions and interpretations of a variety of biological phenomena as well as for the interest that Thompson and other phenomenologically inspired enactivists have taken in them. However, we must proceed with caution here. For one, much of the 
material in these notes is merely provisional. We cannot safely assume that a view presented therein is Merleau-Ponty's considered and final view on any issue. Further, long passages from the course notes consist of Merleau-Ponty reporting to his students the views of other scientists and philosophers concerning the questions at hand. It is thus not always clear whether MerleauPonty is stating a position he himself endorses or if he is simply relaying the views of others. This is especially true of the fascinating yet exegetically problematic discussions of the views of Jakob Johann von Uexküll in the course from 1957-1958. ${ }^{27}$ It is in those pages that we find a passage and an expression very similar to others found in enactivist writings. There, MerleauPonty writes that "In order to grasp the world of the animal, we must not only make perception intervene, but also behaviors, because these deposit a surplus of signification on the surface of objects." ${ }^{28}$ Enactivists, too, often speak of a "surplus" of meaning (or significance) to describe the added value that an organism's environment has for it as opposed to the merely objective description of the same surroundings. ${ }^{29}$ In Mind in Life (from 2007), Thompson follows Varela in this usage ${ }^{30}$, but without direct reference to Merleau-Ponty. Later, in a follow-up discussion of Mind in Life from 2011, Thompson again returns to the idea, this time directly citing Merleau-Ponty. In order to keep track of who (von Uexküll, Merleau-Ponty, and Thompson) said what, I quote at length Thompson quoting Merleau-Ponty discussing von Uexküll:

When Merleau-Ponty writes, in his lecture course on Nature (discussing von Uexküll), "the reactions of the animal in the milieu . . . behaviors ... deposit a surplus of significance on the surfaces of objects," his description applies also to microbial life: the reactions of the bacteria in their milieu-their tumbling and directed swimmingdeposit a surplus of significance on the surfaces of molecules. $^{31}$

But this simply raises the question: Does Merleau-Ponty's description of animal behavior also apply to microbial life? And this we must ask both substantively (is it in fact so) and exegetically (did Merleau-Ponty in fact claim this in his writings).

As the exegetical question is somewhat easier to answer, we begin with it. A fuller look at the context in Merleau-Ponty's Nature course in which the passage occurs is helpful here:

The higher animal [...] constructs an Umwelt that has a Gegenwelt, a rejoinder in its nervous system. In his work in 1934, Uexküll specifies this notion of Gegenwelt. He distinguishes the Welt (the objective world), the Umwelt (the milieu tailored to the animal), and the Gegenwelt, which is the Umwelt of higher animals; the interiorized 
Umwelt is in its turn made up of two systems: the Merkwelt and the Wirkwelt. The Merkwelt depends on the way in which the sense organs are made. These realize a classification of stimuli according to a disposition proper to the animal. The Merkwelt is a "grill" interposed between the animal and the world. In order to determine the world of the animal, we have yet to make the Wirkwelt intervene; that is, the reactions of the animal in the milieu, the melodies of impulses. In order to grasp the world of the animal, we must not only make perception intervene, but also behaviors, because these deposit a surplus of signification on the surface of objects. ${ }^{32}$

Whatever challenges may surround the interpretation of these passages, two things should be clear. First, the discussion is expository. Merleau-Ponty is here relaying the views of von Uexküll without himself evaluating them. As such, we do not know whether Merleau-Ponty himself endorses von Uexküll's position, and the broader context does not settle the question. Second, and more importantly, we see that von Uexküll's substantive view (contra Thompson's appropriation of the passage in question) is that "depositing a surplus of signification on the surface of objects" is something higher animals do and that lower animals precisely do not do. This ability is due to differences between the nervous systems of higher and lower animals. Indeed, just prior to this, Merleau-Ponty, again in an expository voice, has related that the Gegenwelt of the higher animal is a "new phenomenon" 33 as opposed to the Umwelt of the lower animal, with which the lower animal (such as the sea anemone) constitutes a sort of "cohesion" or "closed unity." 34 If lower animals do not "deposit a surplus of significance on the surface of objects," then surely neither do much simpler unicellular organisms.

I find no textual warrant, then, across Merleau-Ponty's various works, for applying phenomenologically informed descriptions of (higher) animal sense-making activity to creatures without nervous systems. That is, on the textual basis, there is no reason to believe that Merleau-Ponty endorsed a phenomenological version of the life-mind continuity thesis that is coextensive with Thompson's and Jonas'. However, there remains the substantive question. Is Thompson correct to say that, in fact, von Uexküll's description also applies to unicellular life? My view here is that if that particular description is meant to be understood phenomenologically (that is, as determining the phenomenological dimension of the life-mind continuity thesis), then the answer is no. The reason is simple. The phenomenological descriptions that Jonas and Thompson would like to apply to unicellular life were fashioned by phenomenologists to describe phenomenal consciousness. Paradigmatically, such concepts and terminology were designed to describe human experience. With suitable caution and modification, we may also apply them to what we posit to be the phenomenal experience of nonhuman 
animals, assuming we have good reason to believe certain animals have such phenomenal experience. Indeed, as I have argued elsewhere following Merleau-Ponty, the reconstruction of the lived world of the animal is a necessary task for the rigorous study of animal behavior. ${ }^{35}$ However, it is in the domain of phenomenal experience and this domain alone that phenomenological descriptions have their sense. To what extent is such phenomenal consciousness distributed throughout the organic domain? Though at present we do not know for certain, Thompson's view in Mind in Life is the following:

There is no good reason [...] for thinking that autopoietic selfhood of the minimal cellular sort involves any kind of intentional access on the part of the organism to its sensemaking. [...] [I]t seems unlikely that minimal autopoietic selfhood involves phenomenal selfhood or subjectivity, in the sense of a prereflective self-awareness constitutive of a phenomenal first-person perspective [...]. Rather, this sort of awareness would seem to require (in ways we do not yet fully understand) the reflexive elaboration and interpretation of life processes provided by the nervous system. ${ }^{36}$

But where there is no phenomenal experience, there is nothing for phenomenology to describe and illuminate, nothing for phenomenological concepts to apply to. In short, no phenomenality, no phenomenology. Applying phenomenological language where there is no phenomenality to describe has brought about much confusion within enactivism. It has prompted critique of the phenomenologically informed notion of sensemaking from enactivists who are indifferent towards phenomenology $\mathrm{y}^{37}$, and inspired some to urge that enactivism must take leave of its phenomenological heritage. ${ }^{38}$ The phenomenological dimension of the lifemind continuity thesis makes much more sense, however, if we restrict its application to sentient beings - that is, if we follow Merleau-Ponty rather than Jonas. ${ }^{39}$

\section{Merleau-Ponty and contemporary psychology on human and chimpanzee cognition}

\section{A discontinuity thesis? The difference between the cognition and experience of humans and other higher animals}

In this section, I will make a small contribution to a Merleau-Pontian phenomenological life-mind continuity thesis that might replace the Jonasian one currently endorsed by Thompson and other enactivists. I will not attempt 
to determine what the minimal instance of phenomenal selfhood is in the organic domain. Presumably, it will be found among an animal species with a nervous system much simpler than that of the human being.

Instead of focusing on this end of the spectrum, I would like to investigate the continuity and discontinuity between human phenomenal experience and that of our closest nonhuman kin. In Structure, Merleau-Ponty describes discrete higher and lower structures of behavior. However, he also maintains that these discrete structures do not correspond to discrete groups of animals, as though the difference between higher and lower behavior were itself entirely discrete. There is no species of animal, Merleau-Ponty claims, whose behavior never rises above the most basic behavioral structure (the syncretic forms), just as there is no species whose behavior never descends below the most complex (the symbolic forms). Still, he claims, "animals can be distributed along this scale according to the type of behavior which is most typical of them." 40 This scale would constitute a continuum of lower to higher animals viewed from Merleau-Ponty's phenomenological perspective on perception and behavior - a phenomenological life-mind continuity thesis.

This simplistic approach to continuity, however, is problematized by the fact that in Structure and other texts from the ensuing decade, Merleau-Ponty also often makes rather strong claims concerning the discontinuity between the human mind and experience and those of nonhuman animals. In Structure, in a discussion of the human order (emergent from the vital order), he states that "the word 'life' does not have the same meaning in animality and humanity." 41 In a public summary and defense of the main ideas of Phenomenology of Perception, Merleau-Ponty claims that "man perceives in a way different from any animal." ${ }^{2}$ And in a discussion of Wolfgang Köhler's The Intelligence of Apes ${ }^{43}$, Merleau-Ponty complains that both the Gestalt psychologists and the general public have missed what was most remarkable in Köhler's research. For Merleau-Ponty, this was not the somewhat formal analogy between the ways in which humans, apes, and other animals actively structure (Gestaltung) their perceptual-behavioral worlds. Rather, he would like to see more emphasis put on the contrasts between human and nonhuman primate cognition. "If [Köhler's] The Mentality of Apes proves anything," he writes, "it is that one cannot attach the same meaning to intelligence when referring to animals as when referring to human beings." 44

We find a more nuanced statement of what Merleau-Ponty takes this essential difference in perception and intelligence to be in Structure and in Merleau-Ponty's early Sorbonne lectures. Representative of these is the following passage, from the lectures of 1951-1952:

Köhler studied the differences between animal and human intelligence [...]. Chimpanzees are capable of conferring new meanings on objects which are not naturally connected with them (e.g., they use a stick to get bananas). The old and 
naturally established totality is destroyed in order to establish a new one. This operation merits the name of intelligence. However, this form of intelligence is different from human intelligence in the following ways: first, optical contact is necessary. The stick must not be too distant from the goal to be attained for the animal to think of using it. The relation of means to goal cannot be stretched to infinity. The animal does not make use of time and space in the way that humans do. Second, one object cannot take on two roles at the same time. The box can have two significations, but only alternately; for example, it is either a seat or a ladder. The animal does not identify the object via the two meanings. The box does not remain the same throughout its two functions. Chimpanzees do possess intelligence, but it is an intelligence which is expended in the moment. [...] [By contrast, for humans] a plurality of aspects can be perceived as part of one single thing. ${ }^{45}$

We can read Merleau-Ponty here as providing an illustrative account of what is meant by "depositing a surplus of significance on the surface of objects." Like humans, chimpanzees are capable of giving a new perceptualbehavioral meaning to an object. In the problem-solving context, what was previously just a natural object lying about in the environment suddenly becomes a tool with a radically new application: it can be used to extend the chimp's reach so as to obtain an objective that was hitherto out of reach. "To reason," Merleau-Ponty summarizes, "is not just to perceive relations between two objects; it is to perceive between them a new or third relation." 46

However, Merleau-Ponty urges that there are critical differences between human and chimpanzee intelligence. First, he maintains that for the chimpanzee to be able to achieve this new "conferral of meaning," the object upon which the new meaning is conferred cannot be too remote in time and space from the new context in which it is to be applied. This is different from human intelligence, which, presumably, can overcome a much greater spatiotemporal distance between the object whose meaning is to be reconceived and the context in which it is to be applied. Indeed, neither need even be really present, as human problem-solving often operates in an entirely imaginary-visual or symbolic modality. Second, Merleau-Ponty claims that when the chimpanzee confers a new meaning upon the object, it necessarily abolishes the old one. If it had previously used the box as a ladder to obtain a suspended objective, but it is now currently using the box as a seat, the old meaning (box-as-ladder) has now been utterly annihilated to make room for the new one (box-as-seat). For the human, by contrast, these two meanings can be retained simultaneously, or perhaps one remains present in its possibility even while another is being actualized (box-as-seat(-but-alsopotentially-as-ladder)). Merleau-Ponty makes this point elsewhere with a 
colorful analogy. Animal intelligence, he says, exhausts itself "kaleidoscopically" when it produces a new landscape for action. ${ }^{47}$ Human intelligence, by contrast, is presumably capable off a superimposition of meanings, in which the old are still retained, visible in their virtuality, as it were.

Merleau-Ponty first made these claims seventy-five years ago. The study of animal behavior was still relatively young at the time. Merleau-Ponty bases much of his understanding of chimpanzee behavior on Köhler's revolutionary The Mentality of Apes. The ensuing decades have seen an astonishing proliferation of research on animal intelligence and behavior. Chimpanzees have been an especially well studied species, often in a comparative context, and the past few decades have garnered remarkable and insightful findings. How do Merleau-Ponty's claims hold up in light of this recent research?

Merleau-Ponty claims that "optical contact" is required between the object upon which a new meaning is bestowed and the context in which its new meaning belongs in order for the chimpanzee to accomplish such meaning bestowal. The idea that the animal lives in a closed hic et nunc and is incapable of transposing itself into an imagined reality has a long pedigree in human-animal comparisons in philosophy and psychology. ${ }^{48}$ This view has come under pressure in recent years, however, from studies on animal episodic memory and future planning. In some cases, a chimpanzee must inhibit a current desire in order to secure an objective for later - for example, suppressing the desire to go after a hidden food cache that only it knows about until a later time when no higher-ranking group members, who might well pull rank and confiscate the snack, will be present. And Frans de Waal tells the story of a chimpanzee who trekked over a half kilometer with a fifteen-pound stone on its back. It then used this stone to break open nuts beneath an especially bountiful palm tree. Clearly, when the chimpanzee conferred the meaning "stone-as-nutcracker" on the rock, it had no "optical contact" with the problem-solving context in which it would eventually apply it. Further interpretation would be required, but such examples at least make a strong prima facie claim to refute Merleau-Ponty's first purported difference between human and ape cognition. ${ }^{49}$

What about the second point, the claim that the chimpanzee's perspectival cognition is not of the same kind as that of the human? Remarkably, there is a striking convergence between Merleau-Ponty's view and the one espoused in the most recent work in comparative psychology and primatology by Michael Tomasello. ${ }^{50}$ Tomasello maintains that chimpanzees never achieve properly perspectival cognition. This is because to achieve a properly perspectival view on an object one must be capable of grasping that there are other, different possible perspectives on one and the same thing. In human development, this occurs through the development of social cognition in the first years of life. Through social interaction, children learn to compare their own experience and perspective on the world with those of others. This 
development occurs in stages, but the traditional test of mature perspectival cognition is the false belief test. To pass this test, the subject must demonstrate that it understands that another person may have a false belief about the way the world is and will act in accordance with this false knowledge rather than the way the world in fact is. Under most normal developmental circumstances, children three and younger will fail false belief tests while at around four or five they begin to pass.

Tomasello sums up his view and explains why chimpanzee cognition never arrives at properly perspectival cognition (i.e., the insight that "box-asseat $=$ box-as-ladder"):

$[\mathrm{P}]$ erspective-taking [in the strict sense] requires that a subject imagine more than one way of perceiving or understanding a given entity or situation; there can be no such thing as a single perspective on something without at least the possibility of other perspectives on it. ${ }^{51}$

However, this leaves us with something of a puzzle to explain why chimpanzees do not acquire the kind of perspective-taking that is characteristic of human cognition. Recent research, much of it coming from Tomasello's own labs, has demonstrated that chimpanzees are in fact capable of much more impressive feats of social cognition than had once been thought. Indeed, some of these abilities look to be the direct antecedents of perspectivetaking in the strict sense. Chimpanzees raised in captivity learn to use the pointing gesture with at least some range of application. They can imagine what others perceive (e.g., they can follow the gaze direction of an experimenter, will change their position to see what the experimenter is looking at if their own view is obstructed, and understand when the experimenter's vision is occluded). They understand the specific content of a conspecific's perception. And in recent years, great apes have even succeeded at certain "implicit" measures of false belief, which infants also pass prior to the second year of life. ${ }^{52}$ All told, chimpanzees possess a suite of socialcognitive abilities very similar to that of a two-year-old infant. The infant uses this as a foundation to advance to properly perspectival cognition and an explicit understanding of false belief. The chimpanzee does not. Why?

Tomasello's answer is that, although the chimpanzee is able to imagine what another chimpanzee perceives or knows, he never goes so far as to actively juxtapose such knowledge with his own conflicting perspective or knowledge. Hence, he never gains the insight into perspective, fundamental to human perspective-taking, that multiple discrepant or even contradictory perspectives on the same object can coexist at one and the same time. When the chimpanzee tracks or imagines what another chimpanzee perceives or knows,

[his] own perception of the situation [is] not an object of attention at all (the participant is seeing "through" his 
perceptual experience, not examining it or comparing it to something else). When the participant is imagining [another chimpanzee] seeing something (or not), he is simply tracking her [i.e., the other chimpanzee's] perceptual experience-full stop-irrespective of what he himself is or is not experiencing. Without an awareness of multiple potential ways of seeing the situation, an individual cannot be said to be taking perspectives at all. ${ }^{53}$

Or, to put this in Merleau-Ponty's complementary idiom, the object as the observing chimp sees it and the object as the observed chimp sees it

are two distinct and alternative objects in the behavior of the chimpanzee and not two aspects of an identical thing. In other words, the animal cannot at each moment adopt a point of view with regard to objects which is chosen at its discretion. ${ }^{54}$

Or, again,

Animal activity [...] loses itself in the real transformations which it accomplishes and cannot reiterate them. For man, on the contrary, the tree branch which has become a stick will remain precisely a tree-branch-which-has-become-astick, the same thing in two different functions and visible for him under a plurality of aspects. ${ }^{55}$

But this solution only passes the explanatory buck one step down the line. For we must now ask why, though the chimpanzee is capable of imagining the experience of another chimpanzee, it never achieves the active juxtaposition of its own perspective with that of the other chimpanzee. In humans, as we have seen, this ability reaches its mature form somewhere around four years of age and constitutes a decisive departure from the shared great ape cognition that younger children demonstrate. Is such cognitiveperceptual perspective-taking intrinsically different in kind from the abilities shared between humans and apes that precedes it? Should it be treated as a continuous development from previous abilities that for some contingent reason the chimpanzee never undergoes? What is the role of language and other higher-order elements of human cognition in this development? And what does this apparent discontinuity entail for the continuity between human and chimpanzee experience within the phenomenological dimension of the life-mind continuity thesis?

\section{Continuity restored: A developmental perspective}

To begin answering these questions, I will now discuss some of the developmental factors that lead up to and, I will suggest, play a formative role in the acquisition of mature, explicit false belief understanding in humans. In 
doing so, I will attempt to chart a more or less continuous trajectory between early infant cognition, in so many respects similar to the cognition of other great apes, and the uniquely human form of perspectival cognition described by Merleau-Ponty and Tomasello.

1. Joint attention. For most of the first year of life, the infant's social interactions primarily occur through a dyadic mode of face-to-face exchanges of vocalizations, gestures, and expressions with caretakers known as protoconversations. Other great apes do not participate in this uniquely human mode of emotional bonding. Towards the end of the first year, the dyadic structure expands to a triadic structure where infant and caretaker are jointly oriented towards an object of interest in the proximate environment. For joint attention to be properly joint, it is not sufficient that infant and caretaker both happen to be attending to the same object. Rather, each individual is attuned also to the attunement of the other to the object. Infants can follow a caretaker's gaze or pointing gesture and now produce their own pointing gestures as well. Chimpanzees, as we have seen, follow gaze and produce pointing gestures. However, their range of motivation for doing so is much more limited than that of the human infant. They point almost exclusively with imperative motivations, in order to get someone to do something for them. Human infants, by contrast, also point to or present objects to caretakers with declarative motivations. A one-year-old infant will share an object with a caretaker just for the sheer joy of sharing it, a sort of extension of the face-to-face emotional connectivity of the protoconversation to include a third term. Further, they will take an interest in the way in which the caretaker is directed towards the object, monitoring how the caretaker emotionally responds to the object and what she does with it. Chimpanzees do not do this. Note, however, that there is no reason to assume that the absence of this behavior is the result of some sort of cognitive deficit. Rather, chimpanzees simply do not appear to be interested in this kind of self-other-object way of interacting. ${ }^{56}$

2. Symbolic play and pretense. Midway through the second year of life, infants begin engaging in symbolic play and other forms of pretense. In symbolic play, the infant behaves with an object as though it were something other than what it is. For example, a banana can serve as a pretend phone, or a block can be treated as though it were a car. Symbolic play is critical for the development of 
perspective-taking and perspectival cognition, for it is practice at deliberately reassigning the use-meaning that the child attaches to an object. Much like pointing, symbolic play appears to be just about uniquely human but not quite. The strongest claims for symbolic play in nonhuman animals - though not the only ones - come unsurprisingly from great apes raised in captivity, especially those who have been given some linguistic training. ${ }^{57}$ This may suggest that apes are in principle capable of symbolic play, but that a suitable environment and models for imitation are required for the ability to come to expression as it does in human children. There is a strong correlation between the development of symbolic play and the development of social cognition and language. ${ }^{58}$

3. Language acquisition. The acquisition of language is correlated with developments in social cognition and likely plays a facilitating role in the formation of a uniquely human mode of perspectival cognition. This is likely because language is pervasively aspectual. In the simplest case, the same object can be described in different ways and can even be designated with different proper and common nouns. The infant's "mommy" also bears a proper name, is perhaps someone's wife, and is the manager of her company. The young child initially struggles with and even rejects the possibility of multiple names for the same thing, but gradually comes to accept and even relish in these possibilities and the aspectual character of language. Another example of the perspectival character of language is of especial interest for present purposes. Verbs that express propositional attitudes - such as "know," "believe," "hope," "fear," etc. - encode the perspective of the sentence subject. Thus, for example, the sentences "the ball is black," "Tom believes the ball is white," and "Jane believes the ball is green" express a perspectival conflict of beliefs between the way the world is and the way people variously believe it to be. In a false belief experiment, Lohman and Tomasello $^{59}$ demonstrated that a brief training session with language can help children at around the threshold age for false belief understanding to pass a false belief test that they had previously failed. The training consisted of presenting the child with an object and asking her what she thinks it is; then presenting new information that reveals the object to be something other than the child initially believed it to be; then asking the child to compare her current and previous beliefs. This training was 
sufficient to help children who had previously failed a standard false belief test to pass the same test. In a control condition, children were given a similar experience with a misleading object, but without the linguistic scaffolding of the experience. This condition did not lead to an improvement on the false belief task.

What these three critical developmental acquisitions from the first years of childhood leading up to explicit understanding of false belief all have in common is that they all make perspective salient. In joint attention, the child is paying attention to the perspective of the caretaker. A potential contrast or conflict - for example, in emotional evaluation of an object of joint attention turns perspective into something of a practical puzzle in the infant's world that requires resolution. In symbolic play, the child is practicing conferring, alternating between, and jointly holding in view contrasting meanings. This is precisely the ability that Merleau-Ponty maintains the chimpanzee is incapable of. In treating the banana as a telephone, the child is playfully and actively exploring the possibility of assigning two meanings to the same object. In doing so, however, she surely never loses sight of the fact that the banana is also something she can eat. Hence, unlike the chimpanzee (who, Merleau-Ponty claims, must "destroy" the previous meaning totality in order to create a new one), the child treating the banana as a phone never loses sight of the identity of the object across its various meanings: banana-as"telephone" = banana-as-food. And in language, the child acquires a representational means that is thoroughly perspectival on various levels. Language offers a way to think about and alternate perspectives that demands a comparatively low cognitive load, as opposed to the comparatively highfidelity, and hence high-load, modes of perspective-switching such as joint attention and symbolic play.

How can we interpret these findings from a phenomenological perspective, and what bearing do they have on the phenomenological dimension of the life-mind continuity hypothesis? I will here draw inspiration from Merleau-Ponty's extensive lectures on developmental psychology to present an interpretation of these facts in the style of Merleau-Ponty's work in this field. ${ }^{60}$ However, my own account departs from Merleau-Ponty's on some points of considerable importance for understanding the phenomenological dimension of life-mind continuity. The reason for the departure, I believe, is that more recent research contradicts some of MerleauPonty's views on both primate and early infant cognition.

My proposal is that through the constant confrontation with perspectives and the practice in perspective-switching and -taking that humans accumulate in childhood, a perspectival, intersubjective perception of the world becomes a habituated and latent component of all normal human experience. ${ }^{61}$ The possibility of seeing an object differently, or of conferring a new meaning upon it, constantly and habitually accompanies human 
perception as a result of our long apprenticeship in switching perspectives and conferring new meanings. We are always at least implicitly, liminally aware that this object could be seen in a different way, or could be put to a new use. And to some extent, we know this about our experience. Chimpanzees are in fact capable of conferring new meanings and seeing things in different ways. However, for want of practice, and for want of a rich intersubjective, linguistic, and cultural world in which assigning new meanings to objects and taking alternative perspectives is a common occurrence, they never habituate this possibility for new perspective into their experience and hence do not know about themselves that they have this capability. Human beings, by contrast, constantly confronted with contrasts and conflicts of perspectives and the possibility of new perspectives, become something like folk theorists of their own and other's perspectives. Or, as Merleau-Ponty puts it in Phenomenology of Perception, there is a "genius for ambiguity that might well serve to define man." ${ }^{\prime 2}$

Does this transformation of the child's experience occur all at once through something like Gestalt switch, a sort of "ah-ha!" moment of insight into the nature of perspective; or does it gradually unfold through steady habituation and practice of perspectival awareness through activities such as joint attention and symbolic play? Research on theory of mind development suggests that preschool-age children acquire different aspects of the understanding of perspective in a sequential manner, though one that varies slightly cross-culturally. ${ }^{63}$ For example, they come to understand that people can have diverse desires for the same object before they understand that people can have diverse beliefs about the same object, and understanding diverse beliefs precedes understanding false beliefs. Whether each of these scaled abilities are acquired all at once or gradually is unknown. The finding, discussed above, that language-scaffolded training sessions can induce success on explicit false belief tasks in children who had previously failed them may seem to suggest an all-at-once development. However, it might simply be that the training teaches children to transfer into an explicit and discursive register something that they already know on a more basic, perceptual level. As for whether language is necessary for full mastery of explicit false belief tests, or whether it simply facilitates such mastery, we simply do not know. My hunch is that the latter is the case. Using language to reason about false beliefs demands a comparatively low cognitive load, and many forms of linguistic expression make perspective salient to us in ways that are relevant for passing false belief tests. It may be possible to arrive at a similar understanding of false belief through, for example, an active empathic simulation of the other's experience. However, this task presents a much heavier cognitive load, and circumstances do not force it upon us in the same way that many conventional linguistic forms do.

Where does this leave the phenomenological dimension of the life-mind continuity thesis? Viewed statically, as it were, comparing the normal 
experience of the adult human with that of the adult chimpanzee, we find that there is a uniquely aspectual character and openness to variability in human experience that is lacking in the chimpanzee's experience. The counterpart of this is the human's ability to take the perspective of another and compare it with her own in ways the chimpanzee never appears to do. These are differences in kind. However, from a genetic perspective, we see these differences in kind may be acquired gradually throughout ontogeny. And their acquisition is driven by a difference in the affective orientation and motivations of the human child. Further, they are scaffolded and facilitated by a linguistic, cultural, and intersubjective milieu uniquely tailored to bring the child's potential for social cognition and language to fruition. In this way, we can recognize the macroscopic discontinuity between human and chimpanzee ways of life and experience, while also restoring a sort of microscopic continuity in development.

On this last point, my own interpretation may soften some of MerleauPonty's starker statements of the discontinuity between the perception and behavior of human and nonhuman animals - between the vital and human orders, as he labels them in Structure. I believe this modification to follow from the current state of knowledge in developmental and comparative psychology, which has advanced considerably in the intervening decades. In addition to the achievements in social cognition discussed above, we now know that chimpanzees in the wild also exhibit cultural learning (e.g., tool use that varies between groups and is passed down across generations). ${ }^{64}$ Meanwhile, Merleau-Ponty also appears to have maintained that even the earliest advancements in infantile perception are necessarily and pervasively social. He seems to have held that the first object of perception is the mother and that it is through her that the infant comes to learn about the material world. Additionally, following the scientific consensus of his time, MerleauPonty did not believe that newborns were capable of visual focus ${ }^{65}$, and hence that it was only somewhat later in the first year that they began to constitute a world of objects - always by way of the face of the other, which is the first "object" for the infant. Hence, for Merleau-Ponty, the "original objects" of "nascent perception" are "the actions of other human subjects." ${ }^{66}$ More recent research on neonatal vision challenges this view. ${ }^{67}$ Though the neonate's power for vision is certainly limited, and it does demonstrate a preference for faces, the vision of neonates and young infants is generally more precocious and robust than Merleau-Ponty knew. As a result, the infant has some access to a world of objects that is not necessarily mediated by the gestures and actions of other humans. Merleau-Ponty's remarks on the importance and precociousness of social perception are surely correct, but he overstates the dependence of object perception on social perception.

The chimpanzee, then, rises above the "purely vital" order to a greater degree than Merleau-Ponty recognized. At the same time, the perception of the human infant is more thoroughly grounded in it and less dependent on 
the human order for the infant's developing relationship to the external world than Merleau-Ponty believed. In this way, we can narrow the gap somewhat between the two orders and add an important qualification to MerleauPonty's claim that the human being perceives in a way different from other animals. This leaves us with a more continuous account of the difference between human and non-human animal cognition and experience than what we find in Merleau-Ponty. At the same time, it is a nuanced account, informed by the most recent empirical research, of the discontinuities Merleau-Ponty was partially right to stress. It thus does justice to his intuitions, which have not been sufficiently acknowledged in the works of phenomenologically inspired enactivists, that there are important differences between the phenomenal experience of human and non-human animals.

\section{Conclusion}

In the preceding discussion, I have attempted to provide a concrete and specific account of phenomenological continuity and discontinuity between the experience of the human being, the prototypical subject of phenomenological description, and that of a nonhuman animal, to whom those same descriptions, we have seen, apply with some modification. In doing so, I hope to have provided a nuanced take on the continuity between the phenomenal experience of these two species that can serve as a model for developing the concrete "phenomenological ethology"68 of nonhuman animals.

What other discontinuous continuities might such concrete investigations discover along an overarching phenomenological life-mind continuity thesis? As we have seen, Merleau-Ponty, following von Uexküll, may have acknowledged a discontinuity between higher and lower animals, with the latter living in a sort of "closed unity" or "cohesion" with their worlds (or Umwelten). By contrast, the higher animal, such as the chimpanzee or human, confers new meanings on objects. How are we to characterize the phenomenal experience (assuming they have such) of those lower animals that have no central nervous system and no precise exteroceptive sense organs? Can such an animal be said to have "objects" at all? Are there animals that have objects, but that are not capable of conferring new meanings on them? What abnormal human experiences might allow us to render more accessible such foreign experiences? And what is it like to be a bat, an octopus, or a worm?

Pursuing such questions with concrete empirical work (both controlled experiments and natural observation) interpreted with the help of phenomenology may provide answers, however provisional and speculative these may need remain. However, it may be that the deeper unity - if there is one - of the phenomenological and empirical dimensions of life-mind continuity will remain obscure so long as both dimensions of investigation are conducted in the absence of an undergirding ontology that clarifies the 
relationship between the phenomenal and the natural. In the meantime, whatever fascinating correlations we discover between phenomenological and empirical investigations will remain just that, correlations. MerleauPonty, from the first lines of Structure, his first book, to the late lectures on the concept of nature, to the final drafts for the unfinished The Visible and the Invisible, was concerned to develop such an ontology that would clarify the place of consciousness in the cosmos. This monumental task still stands before contemporary phenomenology and cognitive science, and the preceding investigations would need to be revised and transcribed within the broader context of such a fundamental ontology. ${ }^{69}$

" I would like to express my gratitude to Talia Welsh and Geoffrey Dierckxsens for comments on earlier versions of this paper.

1 Francisco J. Varela, Evan Thompson, and Eleanor Rosch, The Embodied Mind: Cognitive Science and Human Experience (Cambridge, MA: The MIT Press, 1991).

${ }^{2}$ Varela, Thompson, and Rosch, Embodied Mind, 15.

3 For example, Evan Thompson, Mind in Life: Biology, Phenomenology, and the Sciences of Mind (Cambridge, MA: Harvard University Press, 2007), 128ff.

${ }^{4}$ Paulo De Jesus, “Autopoietic Enactivism, Phenomenology and the Deep Continuity Between Life and Mind," Phenomenology and the Cognitive Sciences 15, no. 2 (2016): 265-289.

${ }^{5}$ Daniel D. Hutto and Glenda Satne, “The Natural Origins of Content," Philosophia 43, no. 3 (2015): 521-536.

6 The first part of this paper further develops themes introduced in Hayden Kee, "Phenomenology and Naturalism in Autopoietic and Radical Enactivism: Exploring Sense-Making and Continuity from the Top Down," Synthese, June 12, 2018, 1-21.

7 Thompson, Mind in Life, 128.

8 Thompson prefers to speak of the "deep continuity of life and mind," and other authors refer to the "strong continuity thesis of life and mind." For brevity's sake, I will refer to it simply as the "life-mind continuity thesis," and will make it clear when I am referring to the specifically phenomenological component of the thesis.

${ }^{9}$ Francisco J. Varela, El Fénomena de La Vida (Santiago: Dolmen Essayo, 2000).

${ }^{10}$ Quoted in Thompson, Mind in Life, 101.

11 Humberto Maturana, "Biology of Cognition," in Autopoiesis and Cognition: The Realization of the Living (Dordrecht: D. Reidel, 1980), 2-58; Thompson, Mind in Life, 124. 
${ }^{12}$ In fact, Thompson himself ultimately remains agnostic as to whether all autopoietic systems are also cognitive systems (Mind in Life, 122-127).

${ }^{13}$ Hans Jonas, The Phenomenon of Life: Toward a Philosophical Biology (Chicago: The University of Chicago Press, 1966), xi; quoted in Thompson, Mind in Life, 129.

14 See though the discussion of a scale along which animals could be distributed according to three hierarchically distinguished structures of behavior typical of them. Maurice Merleau-Ponty, The Structure of Behavior, trans. Alden L. Fisher (Boston: Beacon Press, 1963), $103 f$.

${ }^{15}$ Merleau-Ponty, Structure, 3.

${ }^{16}$ For a thorough discussion of the notion of structure in Structure, and a critique of Thompson's appropriation of it, see Benjamin Sheredos, “Merleau-Ponty's Immanent Critique of Gestalt Theory," Human Studies 40, no. 2 (June 1, 2017): 191-215. I discuss Merleau-Ponty's position and arguments in greater detail in Kee, "Phenomenology and Naturalism"; Hayden Kee, "Phenomenological Reduction in Merleau-Ponty's The Structure of Behavior: An Alternative Approach to the Naturalization of Phenomenology," European Journal of Philosophy (2019).

17 Thompson assumes that they are, identifying the Merleau-Pontian notion of behavior with the concept of cognition. See Thompson, Mind in Life, 126.

18 In an earlier paper, I mistakenly claimed that all the animals discussed in Structure have central nervous systems. This is incorrect. Merleau-Ponty also mentions the starfish $(23,40,104)$ and sea anemone (149), neither of which has a central nervous system. However, while they may not have brains, both creatures do have complex nervous systems. The sea anemone and starfish return as examples of "lower animals" in Merleau-Ponty's later Collège de France course notes on nature. Maurice MerleauPonty, Nature: Course Notes from the College de France, ed. Dominique Seglard, trans. Robert Vallier (Evanston: Northwestern University Press, 2003), $170 \mathrm{ff}$.

${ }^{19}$ Merleau-Ponty, Structure, 104.

${ }^{20}$ Merleau-Ponty, Structure, 104.

${ }^{21}$ Maurice Merleau-Ponty, Child Psychology and Pedagogy: The Sorbonne Lectures 1949-1952, trans. Talia Welsh (Evanston: Northwestern University Press, 2010), 31672.

${ }^{22}$ Merleau-Ponty, Child Psychology, 369.

${ }^{23}$ Merleau-Ponty, Child Psychology, 369; translation modified.

${ }^{24}$ Merleau-Ponty, Child Psychology, 369; translation modified. See also the discussion of tropisms in Structure, $149 \mathrm{f}$. 
25 De Jesus, "Autopoietic Enactivism"; Mario Villalobos and Dave Ward, "Lived Experience and Cognitive Science: Reappraising Enactivism's Jonasian Turn," Constructivist Foundations 11, no. 2 (2016): 204-12.

26 Merleau-Ponty, Child Psychology, 6. For further discussion, see Kee, "Phenomenology and Naturalism."

${ }^{27}$ Merleau-Ponty, Nature, $167 \mathrm{ff}$.

${ }^{28}$ Merleau-Ponty, Nature, $172 \mathrm{f}$.

29 See Francisco J. Varela, “Patterns of Life: Intertwining Identity and Cognition," Brain and Cognition 34, no. 1 (June 1997): 72-87; and, for discussion, Andreas Weber, "The Surplus of Meaning: Biosemiotic Aspects in Francisco J. Varela's Philosophy of Cognition," Cybernetics \& Human Knowing 9, no. 2 (2002): 11-29. I have been unable to determine whether Varela took the expression from his reading of Merleau-Ponty or came up with it independently.

30 Thompson, Mind in Life, 154.

31 Evan Thompson, “Living Ways of Sense Making," Philosophy Today 55, Supplement (2011): 119; quoting Merleau-Ponty 2003, $172 \mathrm{f}$.

${ }^{32}$ Merleau-Ponty, Nature, $172 \mathrm{f}$.

${ }^{33}$ Merleau-Ponty, Nature, 170.

${ }^{34}$ Merleau-Ponty, Nature, 171.

35 It is also required, I have argued, for infant studies. See Maurice Merleau-Ponty, "The Metaphysical in Man," in Sense and Non-Sense, trans. Hubert L. Dreyfus and Patricia Allen Dreyfus (Evanston: Northwestern University Press, 1964), 83-98; Hayden Kee, "Pointing the Way to Social Cognition: A Phenomenological Approach to Embodiment, Pointing, and Imitation in the First Year of Infancy," Journal of Theoretical and Philosophical Psychology (forthcoming).

36 Thompson, Mind in Life, 162.

37 Daniel D. Hutto and Erik Myin, Evolving Enactivism: Basic Minds Meet Content (Cambridge, Mass: The MIT Press, 2017).

38 De Jesus, “Autopoietic Enactivism.”

39 It should be noted that Thompson at times qualifies the phenomenological dimension of the life-mind continuity thesis in ways that bring him closer to the view I am here ascribing to Merleau-Ponty. In a later commentary on Mind in Life, Thompson writes that "A unicellular organism is a self-individuating and sense-making being but not a cognitive one if by 'cognition' we mean being intentionally directed toward objects as unities-in-manifolds having internal and external horizons (call this the phenomenological sense of cognition)." Evan Thompson, "Reply to Commentaries," Journal of Consciousness Studies 18, no. 5-6 (2011): 207. We are left 
to wonder, then, in what sense (if not the phenomenological sense) the unicellular organism can be said to deposit a surplus of signification upon the objects it encounters, if the latter are not understood as the intentional objects experienced by a phenomenal self.

${ }^{40}$ Merleau-Ponty, Structure, 104.

${ }^{41}$ Merleau-Ponty, Structure, 174. Thompson is aware of the passage (Mind in Life, 77), but does not clarify how such an assertion of discontinuity fits with the overarching assertion of phenomenological life-mind continuity.

42 Maurice Merleau-Ponty, The Primacy of Perception: And Other Essays on Phenomenological Psychology, the Philosophy of Art, History, and Politics, ed. James M. Edie (Evanston: Northwestern University Press, 1964), 25.

${ }^{43}$ Wolfgang Köhler, The Mentality of Apes, trans. Ella Winter (London: Routledge and Kegan Paul, 1927); Merleau-Ponty, "The Metaphysical in Man, 83-86.

${ }^{44}$ Merleau-Ponty, "The Metaphysical in Man," 84; translation modified.

${ }^{45}$ Merleau-Ponty, Child Psychology, 430.

${ }^{46}$ Merleau-Ponty, Child Psychology, 430.

${ }^{47}$ Maurice Merleau-Ponty, Signs, trans. Richard McCleary (Evanston: Northwestern University Press, 1964), 81.

48 It is known as the Bischof-Köhler hypothesis, after Doris Bischof-Köhler. BischofKöhler herself cites Wolfgang Köhler as the first to have given thorough expression to the idea. See Doris Bischof-Köhler, Soziale Entwicklung in Kindheit und Jugend: Bindung, Empathie, Theory of Mind (Stuttgart: Kohlhammer Verlag, 2011).

${ }^{49}$ Frans de Waal, Are We Smart Enough to Know How Smart Animals Are? (New York: W. W. Norton \& Company, 2016).

50 The literature is vast, as is Tomasello's own output. For a recent comprehensive statement, see Michael Tomasello, Becoming Human: A Theory of Ontogeny (Cambridge, Massachusetts: Harvard University Press, 2019).

51 Tomasello, Becoming Human, 64.

${ }^{52}$ For a review of the literature and studies on the preceding points, see Tomasello, Becoming Human, 47ff. On the difference between explicit and implicit measures of false belief, see Charlotte Grosse Wiesmann et al., "Implicit and Explicit False Belief Development in Preschool Children," Developmental Science 20, no. 5 (2017).

53 Tomasello, Becoming Human, 64.

${ }^{54}$ Merleau-Ponty, Structure, 116.

${ }^{55}$ Merleau-Ponty, Structure, 175.

56 On protoconversations, see Colwyn Trevarthen, "Communication and Cooperation in Early Infancy: A Description of Primary Intersubjectivity," in Before Speech, ed. M. 
Bullowa (Cambridge: Cambridge University Press, 1979), 321-47. For an overview of the development of joint attention, see Tomasello, Becoming Human, 53ff.

57 Tara Callaghan and John Corbit, "The Development of Symbolic Representation," in Handbook of Child Psychology and Developmental Science: Cognitive Processes, eds. L. S. Liben, U. Müller, and R. M. Lerner, 2nd ed. (Hoboken, NJ: John Wiley \& Sons Inc, 2015), 250-95.

58 Lise M. Youngblade and Judy Dunn, “Individual Differences in Young Children's Pretend Play with Mother and Sibling: Links to Relationships and Understanding of Other People's Feelings and Beliefs," Child Development 66, no. 5 (1995): 1472-92.

59 Heidemarie Lohmann and Michael Tomasello, "The Role of Language in the Development of False Belief Understanding: A Training Study," Child Development 74, no. 4 (August 2003): 1130-44.

60 See Merleau-Ponty, Child Psychology, 148ff. for a discussion of the notion of structuration of perceptual experience. For discussion of Merleau-Ponty's work on developmental psychology, see Talia Welsh, The Child as Natural Phenomenologist: Primal and Primary Experience in Merleau-Ponty's Psychology (Evanston: Northwestern University Press, 2013).

${ }^{61}$ A similar idea can be found in the enactivist account of linguistic sense-making presented in Ezequiel A. Di Paolo, Elena Clare Cuffari, and Hanne De Jaegher, Linguistic Bodies: The Continuity between Life and Language (Cambridge, MA: The MIT Press, 2018).

${ }^{62}$ Merleau-Ponty, Phenomenology, 195/230.

63 Henry M. Wellman and David Liu, "Scaling of Theory-of-Mind Tasks," Child Development 75, no. 2 (April 3, 2004): 523-41; Ameneh Shahaeian, et al., "Culture and the Sequence of Steps in Theory of Mind Development," Developmental Psychology 47, no. 5 (September 2011): 1239-47.

${ }^{64}$ See Gillian L. Vale, et al., "Acquisition of a Socially Learned Tool Use Sequence in Chimpanzees: Implications for Cumulative Culture," Evolution and Human Behavior: Official Journal of the Human Behavior and Evolution Society 38, no. 5 (2017): 63544; Noemie Lamon, et al., "Kin-Based Cultural Transmission of Tool Use in Wild Chimpanzees," Science Advances 3, no. 4 (April 1, 2017).

${ }^{65}$ See Welsh, The Child as Natural Phenomenologist, 46.

${ }^{66}$ Merleau-Ponty, Structure, 166. See also: “Child psychology precisely proposes the enigma of a linguistic consciousness and a consciousness of others which is almost pure and which is prior to that of sonorous and visual phenomena[.]" (171f.) Though the claims to "almost" purity and priority here would require some interpretation, Merleau-Ponty's argument in this section of Structure appears to be that the infant 
only ever attains a surrounding material world by way of a primary form of social interaction.

${ }^{67}$ Mary Courage and Russell Adams, "Visual Acuity Assessment from Birth to Three Years Using the Acuity Card Procedure: Cross-Sectional and Longitudinal Samples," Optometry and Vision Science 67, no. 9 (September 1990): 713-18.

${ }^{68}$ Kee, "Phenomenology and Naturalism."

${ }^{69}$ Gallagher has identified the need for such an ontology of nature for enactivism. Shaun Gallagher, Enactivist Interventions: Rethinking the Mind (Oxford: Oxford University Press, 2017). Jenkinson explores the prospects of the ontology of flesh from Merleau-Ponty's late work as an undergirding ontology for enactivism. John Jenkinson, "Enactive Subjectivity as Flesh," Phenomenology and the Cognitive Sciences 16, no. 5 (2017): 931-951. Bitbol explores the possibility of integrating phenomenology and panpsychism. Michel Bitbol, "Panpsychism in the First Person," in Analytic and Continental Philosophy. Proceedings of the 37th International Wittgenstein Symposium, eds. Harald A. Wiltsche and Sonia Rinofner-Kreidl (De Gruyter, 2016), 122; Michel Bitbol, "Beyond Panpsychism: The Radicality of Phenomenology," in Self, Culture and Consciousness, eds. Sangeetha Menon, Nithin Nagaraj, and V. V. Ninoy (Berlin: Springer, 2018), 337-56. Morris offers an original interpretation of MerleauPotny's efforts to locate meaning in nature in his later ontology. David Morris, Merleau-Ponty's Developmental Ontology (Evanston: Northwestern University Press, 2018). 